\title{
Distribución espacial y temporal de Elmidae (Insecta: Coleoptera) y su relación con los parámetros fisicoquímicos en el río Ocoa, Meta, Colombia
}

\author{
(D) Ivonne Alexandra Aguilera-Giraldo1, (D) Jesús Manuel Vásquez-Ramos ${ }^{2, *}$ \\ ${ }^{1}$ Grupo de Investigación en Gestión Ambiental Sostenible (GIGAS), Instituto de Ciencias Ambientales \\ de la Orinoquia Colombiana (ICAOC), Universidad de los Llanos, Villavicencio, Colombia \\ ${ }^{2}$ Grupo de Investigación, Evaluación, Manejo y Conservación de Recursos Hidrobiológicos y Pesqueros (GIREHPES), \\ Instituto de Ciencias Ambientales de la Orinoquia Colombiana (ICAOC), Universidad de los Llanos, Villavicencio, Colombia
}

\section{Resumen}

Los élmidos (Coleoptera) son organismos acuáticos de distribución mundial. Sus formas inmaduras y adultas ocupan una amplia gama de sustratos y hábitats, y son un grupo diverso. Este estudio tuvo como objetivo determinar la distribución espacial y temporal de los Elmidae, y su relación con los parámetros fisicoquímicos en el río Ocoa. Se establecieron 15 estaciones de muestreo y se revisaron 210 muestras de macroinvertebrados recolectadas en un sustrato de roca-guijarro utilizando una red Surber $(250 \mu \mathrm{m})$ en dos periodos hidrológicos contrastantes (de baja y alta precipitación), correspondientes a octubre de 2014 y febrero de 2015. Se obtuvieron 37 organismos (larvas y adultos) de nueve géneros de Elmidae: Heterelmis, Huleechius, Macrelmis, Astrolimnius, Microcylloepus, Neoelmis, Hexacylloepus, Cylloepus, Notelmis y Phanocerus, de los cuales siete corresponden a nuevos registros para la región de la Orinoquia colombiana. En el periodo de baja precipitación hubo una mayor representatividad, con 35 registros de nueve géneros, en tanto que en el periodo de alta precipitación hubo una marcada disminución de la riqueza, con dos registros solamente, correspondientes a dos géneros. En general, la abundancia de Elmidae fue baja a lo largo del río, y en las estaciones ubicadas en el sector que atraviesa la ciudad de Villavicencio, con mayor deterioro del hábitat, se registró la menor abundancia y en algunas no se registraron élmidos. Los efectos ambientales de la urbanización, como la contaminación por materia orgánica y la proliferación de coliformes debida al vertimiento de aguas residuales, fueron los principales factores determinantes de la disminución de la riqueza y la abundancia de estos organismos. Esta es la primera exploración de Elmidae en la zona y contribuye al conocimiento ecológico de la fauna de coleópteros en cuencas urbanas de la Orinoquia colombiana. C 2019. Acad. Colomb. Cienc. Ex. Fis. Nat.

Palabras clave: Bioindicador; Coleoptera; Elmidae; Cuenca urbana; Orinoco.

Spatial and temporal distribution of EImidae (Insecta: Coleoptera) and its relationship with physicochemical parameters in the Ocoa river, Meta, Colombia

\begin{abstract}
The riffle beetle (Coleoptera) are aquatic organisms of worldwide distribution. Their immature and adult forms occupy a wide range of substrates and habitats and they are a diverse group. Our study aimed to determine the spatial and temporal distribution of the family Elmidae and its relationship with physicochemical parameters in the Ocoa River. We established 15 sampling stations and reviewed a total of 210 samples of macroinvertebrates collected in the rock-pebble substrate using Surber nets $(250 \mu \mathrm{m})$ in two contrasting hydrological periods (low and high rainfall): October 2014 and February 2015. We obtained 37 organisms (larvae and adults) from nine genera of Elmidae: Heterelmis, Huleechius, Macrelmis, Astrolimnius, Microcylloepus, Neoelmis, Hexacylloepus, Cylloepus, Notelmis and Phanocerus, of which seven corresponded to new records for the Colombian Orinoquia region. During the low rainfall period, the representation was higher, with 35 records of nine genera, while during the high rainfall period, there was a marked decrease in richness, with only two records corresponding to two genera. In general, the abundance of Elmidae was low along the river; the stations located in the sector crossing the city of Villavicencio, with a more deteriorated habitat, harbored the lowest abundance and in some, no riffle beetles were registered. The environmental effects of urbanization, such as contamination by organic matter and the growth of coliform bacteria due to wastewater discharges, were the main determinants of the decrease in the richness and abundance of these organisms. The present study is the first exploration of Elmidae in the zone and contributes to the ecological knowledge of Coleoptera fauna in urban basins of the Colombian Orinoquia. (C) 2019. Acad. Colomb. Cienc. Ex. Fis. Nat.
\end{abstract}

Key words: Bioindicator; Coleoptera; Elmidae; Urban basin; Orinoco.

\footnotetext{
*Correspondencia:

Jesús Manuel Vásquez Ramos; jvasquez@unillanos.edu.co; Recibido: 3 de febrero de 2019; Aceptado: 15 de marzo de 2019 ;

Editor: Elizabeth Castañeda
} 


\section{Introducción}

Los élmidos son escarabajos acuáticos de amplia distribución, con cerca de 1.500 especies descritas a nivel mundial que se distribuyen en 149 géneros (Slipinski, et al., 2011). Pertenecen al orden Coleoptera, el cual incluye cerca de 18.000 especies netamente acuáticas, distribuidas en aproximadamente 30 familias (Jäch \& Balke, 2008). En el Neotrópico la familia Elmidae tiene una amplia distribución y está representada por dos subfamilias: Elmidae, con 385 especies y 36 géneros, y Larainae, con 50 especies y 11 géneros (Manzo, 2013).

La diversidad de este grupo probablemente se deba a que ocupa un amplio espectro de microhábitats en ambientes lóticos y en algunos lénticos (White \& Roughley, 2008), pues las larvas y los adultos pueden colonizar sustratos como plantas acuáticas, barro, raíces, troncos, piedras, hojarasca y, también, los márgenes de ecosistemas acuáticos o lo que se conoce comúnmente como el hábitat ripario (Ferreira-Jr, et al., 2014; Salles \& Ferreira-Jr, 2014).

Durante su ciclo de vida, la mayoría de los élmidos se alimentan principalmente de algas y detritos (Brown, 1987) y presentan de cuatro a ocho estadios larvales seguidos de un estadio de pupa y el de adulto, aunque con diferencias entre las subfamilias Elminae y Laraine (Brown, 1987; White \& Roughley, 2008). Son importantes en las cadenas tróficas de los ecosistemas acuáticos porque procesan la materia orgánica $y$, en alguna medida, son fuente de alimento de peces y aves acuáticas (Brown, 1987; White \& Roughley, 2008).

En los últimos años, la investigación sobre los Elmidae neotropicales ha aumentado, no solo por su diversidad, sino por su potencial como bioindicador, pues las larvas y los adultos de la mayoría de las especies se encuentran en aguas corrientes bien oxigenadas y presentan baja tolerancia a la contaminación orgánica, lo que permite la formulación de índices de calidad ambiental en muchas corrientes neotropicales (Von Ellenrieder, 2007; Archangelsky, et al., 2009; Gutiérrez-Fonseca, 2010; Manzo, 2013; Braun, et al., 2014; Lozano, 2014; González-Córdoba, et al., 2015a).

En Colombia el estudio taxonómico y ecológico del orden Coleoptera ha sido muy escaso en comparación con el de otros órdenes de insectos como Ephemeroptera y Trichoptera (Roldán, 2016). Aunque se han publicado varios trabajos sobre este orden (González-Córdoba, et al., 2015a), su complejidad taxonómica y su poca abundancia no han fomentado el interés por estudiarlo. En el último año han aparecido algunos aportes con un alto rigor taxonómico que han enriquecido el conocimiento ecológico, taxonómico y de distribución de géneros y especies de la familia Elmidae en la regiones andina y pacífica, y en la Orinoquia (González-Córdoba, et al., 2015a, b, 2016a,b, 2019); sin embargo, deben aunarse esfuerzos para estudiar la riqueza genérica y de especies de la familia en otras regiones del país (González-Córdoba, et al., 2016b).
Específicamente en la Orinoquia, González-Córdoba, et al. $(2015 b, 2019)$ han registrado cinco especies (Neolimnius palpalis, Hinton 1939, Pilielmis apama, Hinton 1971, Hintonelmis opis, Hinton 1971, Hintonelmis sul, Hinton 1971 y Stegoelmis stictoides, Spangler 1990) y siete géneros (Hexacylloepus, Microcylloepus, Neoelmis, Stegoelmis, Xenelmis, Gyrelmis e Hyntonelmis). Teniendo en cuenta la multiplicidad de ecosistemas acuáticos, la variación altitudinal y las diferentes afectaciones antrópicas de esta región, existe la posibilidad de muchos hallazgos. En este contexto, el presente estudio se llevó a cabo en el área urbana y suburbana del río Ocoa, subcuenca del río Orinoco en Colombia, con el objetivo de determinar la distribución espacial y temporal de la familia Elmidae (Coleoptera) y establecer posibles relaciones de los géneros registrados con algunas variables físicas y químicas del agua, para así aportar al conocimiento de este grupo en la región de la Orinoquia.

\section{Metodología}

Area de estudio. Los muestreos se llevaron a cabo en un rango de altura de 241 a $532 \mathrm{~m}$ s.n.m. en un área urbana y suburbana de la cuenca hidrográfica del río Ocoa, con un área de 28.290 ha, ubicada en el municipio de Villavicencio, Colombia. El río nace en la vereda Samaria a 1.155 m s.n.m. y desemboca en el río Guatiquía, en el sector de Murujuy, a $225 \mathrm{~m}$ s.n.m. Al norte, la cuenca está delimitada por las estribaciones de la cordillera Oriental y la cuenca del río Guatiquía; al oriente con el municipio de Puerto López; por el sur con las cuencas de Caños Negros, Quenane, Pachaquiaro y Chocho, y por el occidente, con el río Guayuriba (Torres-Mora, et al., 2015).

Material biológico. El material biológico se recolectó en el marco del proyecto "Identificación de alternativas de manejo ambiental de los ríos Guayuriba y Ocoa y caños Quenane y Quenanito de la cuenca alta del río Meta, basado en estrategias educativas, investigativas y de proyección social", objeto del convenio marco de colaboración No. 5211592 suscrito entre la Universidad de Los Llanos y Ecopetrol.

Los muestreos se hicieron en dos periodos hidrológicos (de altas precipitaciones y de bajas precipitaciones), correspondientes a octubre de 2014 y febrero de 2015, en 15 estaciones a lo largo del río seleccionadas teniendo en cuenta la accesibilidad al lugar y la actividad antrópica (Tabla 1). En cada estación se tomaron siete muestras en sustrato rocoso con redes Surber $(250 \mu \mathrm{m}$ de ojo de malla, 30x30 $\mathrm{cm}) \mathrm{y}$, posteriormente, se fijaron con alcohol (70 \%).

El material así dispuesto se trasladó al Instituto de Ciencias Ambientales de la Orinoquia (ICAOC) y mediante el uso de estereoscopios los élmidos se limpiaron, se separaron y se determinaron hasta el mínimo nivel taxonómico posible empleando las claves de Archangelsky, et al. (2009), Manzo (2005), y González-Córdoba, et al. (2015b), y con el apoyo de consultas a los expertos.

Parámetros fisicoquímicos. Se midieron in situ siete variables: $\mathrm{pH}$ (unidades de $\mathrm{pH}$ ), oxígeno disuelto $\left(\mathrm{mgO}_{2} \cdot \mathrm{L}^{-1}\right)$, 
Tabla 1. Estaciones de muestreo establecidas en el río Ocoa

\begin{tabular}{|c|c|c|c|c|c|c|c|}
\hline \multirow[t]{2}{*}{ Estación } & \multirow[t]{2}{*}{ Nombre } & \multicolumn{2}{|c|}{ Coordenadas } & \multirow{2}{*}{$\begin{array}{l}\text { Altitud } \\
\text { m s.n.m. }\end{array}$} & \multirow[t]{2}{*}{ Tipo de afectación } & \multirow{2}{*}{$\begin{array}{l}\text { Vegetación } \\
\text { riparia }\end{array}$} & \multirow[t]{2}{*}{ Uso del suelo } \\
\hline & & $\mathbf{N}$ & $\mathbf{O}$ & & & & \\
\hline 1 & $\begin{array}{l}\text { Confluencia } q / d a \\
\text { Blanca y río Ocoa }\end{array}$ & $04^{\circ} 05^{\prime} 13,3^{\prime \prime}$ & $73^{\circ} 42^{\prime} 32,6^{\prime \prime}$ & 532 & $\begin{array}{l}\text { Vertimientos domésticos de } \\
\text { fincas, casas aledañas }\end{array}$ & $\begin{array}{l}\text { Árboles, } \\
\text { arbustos y } \\
\text { herbáceas }\end{array}$ & $\begin{array}{l}\text { Residencial } \\
\text { y ganadería }\end{array}$ \\
\hline 2 & San Luis de Ocoa & $04^{\circ} 04^{\prime} 45,8^{\prime \prime}$ & $73^{\circ} 42^{\prime} 18,2^{\prime \prime}$ & 504 & $\begin{array}{l}\text { Vertimientos domésticos de } \\
\text { caseríos, empresas avícolas y uso } \\
\text { para recreación }\end{array}$ & $\begin{array}{l}\text { Árboles, } \\
\text { arbustos y } \\
\text { herbáceas }\end{array}$ & Residencial \\
\hline 3 & Puente Caído & $04^{\circ} 06^{\prime} 13,5^{\prime \prime}$ & $73^{\circ} 37^{\prime} 58,9^{\prime \prime}$ & 419 & $\begin{array}{l}\text { Vertimientos residenciales } \\
\text { e industriales de aceiteras, } \\
\text { termoeléctrica, empresas } \\
\text { piscícolas, plantas de sacrificio } \\
\text { de pollos, lavados de automóviles } \\
\text { y porquerizas }\end{array}$ & $\begin{array}{l}\text { Árboles, } \\
\text { arbustos y } \\
\text { gramíneas }\end{array}$ & Residencial \\
\hline 4 & $\begin{array}{l}\text { Antes de Caño } \\
\text { buque }\end{array}$ & $04^{\circ} 06^{\prime} 19,6^{\prime \prime}$ & $73^{\circ} 37^{\prime} 25,3^{\prime \prime}$ & 420 & $\begin{array}{l}\text { Vertimientos residenciales, } \\
\text { industriales y lavaderos de autos }\end{array}$ & $\begin{array}{l}\text { Árboles, } \\
\text { arbustos y } \\
\text { herbáceas }\end{array}$ & Residencial \\
\hline 5 & Caño Buque & $04^{\circ} 06^{\prime} 44,8^{\prime \prime}$ & $73^{\circ} 37^{\prime} 05,2^{\prime \prime}$ & 415 & $\begin{array}{l}\text { Vertimientos residenciales } \\
\text { y desechos que recoge caño } \\
\text { Buque en el casco urbano de } \\
\text { Villavicencio }\end{array}$ & $\begin{array}{l}\text { Árboles, } \\
\text { arbustos y } \\
\text { herbáceas }\end{array}$ & Residencial \\
\hline 6 & Puente Chorillano & $04^{\circ} 06^{\prime} 42,98^{\prime \prime}$ & $73^{\circ} 36^{\prime} 20,5^{\prime \prime}$ & 399 & $\begin{array}{l}\text { Vertimientos de urbanizaciones, } \\
\text { lavaderos de automóviles y } \\
\text { restaurantes o asaderos }\end{array}$ & $\begin{array}{l}\text { Árboles y } \\
\text { arbustos }\end{array}$ & Residencial \\
\hline 7 & $\begin{array}{l}\text { Antes de Caño La } \\
\text { Cuerera }\end{array}$ & $04^{\circ} 06^{\prime} 42,3^{\prime \prime}$ & $73^{\circ} 34^{\prime} 19,4^{\prime \prime}$ & 381 & $\begin{array}{l}\text { Vertimientos residenciales e } \\
\text { industriales }\end{array}$ & $\begin{array}{l}\text { Árboles, } \\
\text { arbustos y } \\
\text { gramíneas }\end{array}$ & Residencial \\
\hline 8 & Caño Cuerera & $04^{\circ} 06^{\prime} 50^{\prime \prime}$ & $73^{\circ} 34^{\prime} 20^{\prime \prime}$ & 381 & $\begin{array}{l}\text { Vertimientos de urbanizaciones e } \\
\text { industrias; cerca de esta estación } \\
\text { quedaba un depósito de basuras }\end{array}$ & $\begin{array}{l}\text { Árboles, } \\
\text { arbustos y } \\
\text { herbáceas }\end{array}$ & Residencial \\
\hline 9 & $\begin{array}{l}\text { Posterior a caño } \\
\text { La Cuerera }\end{array}$ & $04^{\circ} 06^{\prime} 41,0^{\prime \prime}$ & 733'서, & 377 & $\begin{array}{l}\text { Vertimientos residenciales, } \\
\text { industriales y lixiviados de un } \\
\text { antiguo relleno sanitario }\end{array}$ & $\begin{array}{l}\text { Árboles, } \\
\text { arbustos y } \\
\text { herbáceas }\end{array}$ & Residencial \\
\hline 10 & $\begin{array}{l}\text { Antes de Caño } \\
\text { Maizaro }\end{array}$ & $04^{\circ} 06^{\prime} 30,5^{\prime \prime}$ & $73^{\circ} 33^{\prime} 43,8^{\prime \prime}$ & 374 & $\begin{array}{l}\text { Vertimientos domésticos de } \\
\text { fincas cercanas al cauce y } \\
\text { actividades de ganadería }\end{array}$ & $\begin{array}{l}\text { Árboles, } \\
\text { arbustos y } \\
\text { herbáceas }\end{array}$ & $\begin{array}{l}\text { Residencial } \\
\text { y agrícola }\end{array}$ \\
\hline 11 & Caño Maizaro & $04^{\circ} 06^{\prime} 30^{\prime \prime}$ & $73^{\circ} 30^{\prime} 40^{\prime \prime}$ & 345 & $\begin{array}{l}\text { Vertimientos domésticos y } \\
\text { desechos por llantas, plásticos, } \\
\text { colchones, papeles, entre otros, } \\
\text { provenientes de la ciudad }\end{array}$ & $\begin{array}{l}\text { Árboles, } \\
\text { arbustos y } \\
\text { herbáceas }\end{array}$ & $\begin{array}{l}\text { Agrícola, } \\
\text { residencial } \\
\text { y ganadería }\end{array}$ \\
\hline 12 & $\begin{array}{l}\text { Posterior a caño } \\
\text { Maizaro }\end{array}$ & $04^{\circ} 06^{\prime} 32,9^{\prime \prime}$ & 7330’39,2”' & 345 & $\begin{array}{l}\text { Vertimientos domésticos e } \\
\text { industriales y actividades de } \\
\text { ganadería cercanas al río. }\end{array}$ & $\begin{array}{l}\text { Árboles, } \\
\text { arbustos y } \\
\text { herbáceas }\end{array}$ & $\begin{array}{l}\text { Agrícola y } \\
\text { ganadería }\end{array}$ \\
\hline 13 & $\begin{array}{l}\text { Vertimiento de } \\
\text { Ecopetrol-Apiay }\end{array}$ & $04^{\circ} 06^{\prime} 48,4^{\prime \prime}$ & $73^{\circ} 22^{\prime} 50,0^{\prime \prime}$ & 259 & $\begin{array}{l}\text { Vertimientos domésticos e } \\
\text { industriales y vertimiento de } \\
\text { aguas asociadas a actividades de } \\
\text { explotación de hidrocarburos }\end{array}$ & $\begin{array}{l}\text { Árboles, } \\
\text { arbustos y } \\
\text { herbáceas }\end{array}$ & $\begin{array}{l}\text { Agrícola e } \\
\text { industrial }\end{array}$ \\
\hline 14 & Alcaraván & $04^{\circ} 06^{\prime} 59,0^{\prime \prime}$ & $73^{\circ} 21^{\prime} 31,8^{\prime \prime}$ & 276 & $\begin{array}{l}\text { Vertimientos domésticos e } \\
\text { industriales y modificaciones en } \\
\text { el cauce por paso de carros }\end{array}$ & $\begin{array}{l}\text { Árboles, } \\
\text { arbustos y } \\
\text { gramíneas }\end{array}$ & Agrícola \\
\hline 15 & Bocas del Ocoa & $04^{\circ} 07^{\prime} 48,8^{\prime \prime}$ & $73^{\circ} 15^{\prime} 30,1^{\prime \prime}$ & 241 & $\begin{array}{l}\text { Vertimientos domésticos de } \\
\text { fincas aledañas, y de diferentes } \\
\text { cultivos y captación de agua para } \\
\text { cultivo de palma de aceite }\end{array}$ & $\begin{array}{l}\text { Árboles, } \\
\text { arbustos y } \\
\text { gramíneas }\end{array}$ & Agrícola \\
\hline
\end{tabular}


porcentaje de saturación de oxígeno (\% SAT. $\left.\mathrm{O}_{2}\right)$, temperatura $\left({ }^{\circ} \mathrm{C}\right)$, conductividad eléctrica $\left(\mu \mathrm{S} . \mathrm{cm}^{-1}\right)$, caudal $\left(\mathrm{m}^{3} \mathrm{~s}^{-1}\right)$ y velocidad de la corriente $\left(\mathrm{m} . \mathrm{s}^{-1}\right)$. En el laboratorio se midieron 28 parámetros correspondientes a: aceites y grasas, amonio, arsénico, bicarbonatos, cadmio, cobre, cromo, demanda química de oxígeno (DQO $-\mathrm{mgO}_{2} \cdot \mathrm{L}^{-1}$ ), demanda biológica de oxígeno $\left(\mathrm{DBO}_{5}-\mathrm{mgO}_{2} \cdot \mathrm{L}^{-1}\right)$, fenoles totales, fósforo total $\left(\mathrm{mgP.L} \mathrm{L}^{-1}\right)$, hidrocarburos aromáticos policíclicos, hidrocarburos totales, hierro, mercurio, níquel, nitratos $\left(\mathrm{mgNO}_{3} \cdot \mathrm{L}^{-1}\right)$, nitritos $\left(\mathrm{mgNO}_{2} \cdot \mathrm{L}^{-1}\right)$, nitrógeno total, ortofosfatos, pesticidas organoclorados, pesticidas organofosforados, plomo, sólidos totales disueltos (STD - ppm), sulfatos, turbidez (UNT), tensoactivos y zinc, así como dos parámetros bacteriológicos: coliformes fecales y coliformes totales.

Análisis de datos. Se calculó la abundancia relativa de cada género a nivel espacial y temporal. Para determinar la representatividad del muestreo de élmidos se utilizó la diversidad asintótica estimada de la riqueza (Chao, et al., 2014; Chao \& Chiu, 2016) con el paquete iNEXT (Hsieh, et al., 2019) en el programa RStudio (RStudio Team, 2015). La relación entre los élmidos y las variables físicas, químicas y bacteriológicas se estableció mediante un análisis de correspondencia canónica (ACC) usando el programa CANOCO 4.56 (Braak \& Smilauer, 2002; Leps \& Smilauer, 2003), dado el comportamiento unimodal de los datos; además, con el fin de determinar si las variables ambientales explicaban la distribución de élmidos a lo largo del río, se hizo una prueba de permutación de Montecarlo con 499 iteraciones (Leps \& Smilauer, 2003). Dichos análisis se hicieron únicamente con la información de los parámetros fisicoquímicos y bacteriológicos del periodo de baja precipitación; en el periodo de alta precipitación se registraron muy pocos taxones $\mathrm{y}$, por ende, no se pudo hacer este análisis.
Asimismo, se empleó el índice de contaminación por materia orgánica (ICOMO) (Ramírez, et al., 1997) para determinar si la expansión urbana y la contaminación por aguas residuales reflejadas en el oxígeno disuelto (\%), la demanda biológica de oxígeno y los coliformes totales tenían un efecto sobre la riqueza y la abundancia de la familia Elmidae.

\section{Resultados}

Se recolectaron 37 organismos pertenecientes a la familia Elmidae: 36 de la subfamilia Elminae y uno de Larainae. Los géneros más abundantes fueron Huleechius (nueve individuos), Cylloepus (siete individuos) y Macrelmis (seis individuos), y los menos representativos, con tan solo un individuo, fueron Astrolimnius, Heterelmis, Notelmis y Phanocerus (Tabla 2). En cuanto a la diversidad asintótica estimada para q0 a nivel espacial, se encontró que la representatividad del muestreo fue suficiente, pues estuvo entre 66 y $100 \%$ (Tabla 3 ).

Durante los meses de febrero y marzo (baja precipitación) se registró la mayor abundancia $(94,59 \%)$ y riqueza (nueve géneros), en tanto que en el mes de julio (alta precipitación) se registraron dos individuos $(5,40 \%)$ de los géneros Heterelmis y Microcylloepus (Tabla 2).

La estación 1 presentó la mayor riqueza, con cuatro géneros (Huleechius, Neoelmis, Cylloepus y Notelmis), seguida de las estaciones 3 y 15, con tres géneros. En siete estaciones $(6,7,8,9,11,12$ y 13$)$ no se registraron organismos de la familia y el género más frecuente a lo largo del río fue Huleechius, que se registró en cuatro de las 15 estaciones (Tabla 4).

En cuanto a la distribución altitudinal, la mayor riqueza se presentó entre los 415 y 532 m s.n.m., con ocho de los diez hallados. El género con mayor distribución fue Microcylloepus (420, 374 y 276 m s.n.m.), en tanto que

Tabla 2. Composición y abundancia de la familia Elmidae

\begin{tabular}{|c|c|c|c|c|c|c|}
\hline \multirow[t]{2}{*}{ Familia } & \multirow[t]{2}{*}{ Subfamilia } & \multirow[t]{2}{*}{ Género } & \multicolumn{2}{|c|}{ Periodo aguas bajas } & \multicolumn{2}{|c|}{ Periodo aguas altas } \\
\hline & & & $\mathbf{n}$ & $\begin{array}{l}\text { Abundancia } \\
\text { relativa (\%) }\end{array}$ & $\mathbf{n}$ & $\begin{array}{l}\text { Abundancia } \\
\text { relativa (\%) }\end{array}$ \\
\hline \multirow[t]{11}{*}{ Elmidae } & \multirow[t]{9}{*}{ Elminae } & Heterelmis & 0 & 0,00 & 1 & 50 \\
\hline & & Huleechius & 9 & 28,13 & 0 & 0 \\
\hline & & Macrelmis & 6 & 18,75 & 0 & 0 \\
\hline & & Austrolimnius & 1 & 3,13 & 0 & 0 \\
\hline & & Microcylloepus & 4 & 3,13 & 1 & 50 \\
\hline & & Neoelmis & 3 & 9,38 & 0 & 0 \\
\hline & & Hexacylloepus & 3 & 9,37 & 0 & 0 \\
\hline & & Cylloepus & 7 & 21,87 & 0 & 0 \\
\hline & & Notelmis & 1 & 3,12 & 0 & 0 \\
\hline & \multirow[t]{2}{*}{ Larainae } & Phanocerus & 1 & 3,12 & 0 & 0 \\
\hline & & Total: & 35 & 100,00 & 2 & 100 \\
\hline
\end{tabular}


Tabla 3. Diversidad asintótica estimada de la riqueza para el ensamblaje de Elmidae a nivel espacial. Las estaciones no incluidas no registraron ningún género

\begin{tabular}{|c|c|c|c|c|c|c|}
\hline Estación & Observada & Estimada & $\begin{array}{c}\text { Esfuerzo de } \\
\text { muestreo (\%) }\end{array}$ & $\mathbf{E E}$ & LI & $\mathbf{L S}$ \\
\hline 1 & 4,00 & 5,78 & 69,23 & 3,36 & 4,16 & 23,89 \\
\hline 2 & 2,00 & 2,00 & 100,00 & 0,46 & 2,00 & 3,60 \\
\hline 3 & 3,00 & 4,50 & 66,67 & 2,87 & 3,13 & 20,08 \\
\hline 4 & 1,00 & 1,00 & 100,00 & 3,12 & 1,00 & 2,55 \\
\hline 5 & 1,00 & 1,00 & 100,00 & 0,20 & 1,00 & 1,46 \\
\hline 10 & 1,00 & 1,00 & 100,00 & 3,12 & 1,00 & 2,55 \\
\hline 14 & 2,00 & 2,00 & 100,00 & 4,61 & 2,00 & 3,67 \\
\hline 15 & 3,00 & 3,00 & 100,00 & 5,04 & 3,00 & 4,67 \\
\hline
\end{tabular}

EE: error estándar; LI: límite inferior; LS: límite superior

Hexacylloepus, Notelmis y Phanocerus se registraron en una estación a 276, 532 y 276 m s.n.m., respectivamente (Tabla 4).

De las 28 variables físicas, químicas y bacteriológicas medidas ex situ tan solo 19 registraron cambios a lo largo del río (Tabla 5); en el resto, los valores estuvieron por debajo del límite de detección, por lo que se excluyeron del análisis. Es importante resaltar que variables como el $\mathrm{pH}$ y la temperatura exhibieron una reducida variación a lo largo

Tabla 4. Distribución espacial y riqueza de géneros de la familia Elmidae

\begin{tabular}{|c|c|c|c|c|c|c|c|c|c|c|c|}
\hline \multirow[t]{2}{*}{ Estación } & \multirow{2}{*}{$\begin{array}{l}\text { Altitud } \\
\text { m s.n.m. }\end{array}$} & \multirow[b]{2}{*}{ 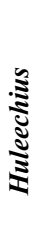 } & \multirow[b]{2}{*}{ 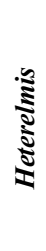 } & \multirow[b]{2}{*}{ 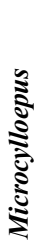 } & \multicolumn{4}{|c|}{ Géneros } & \multirow[b]{2}{*}{$\frac{\mathfrak{s}}{\stackrel{\Xi}{\Xi}}$} & \multirow[b]{2}{*}{ 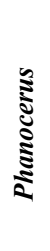 } & \multirow[b]{2}{*}{$\begin{array}{c}\text { Riqueza } \\
\text { (S) }\end{array}$} \\
\hline & & & & & 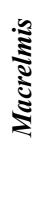 & 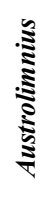 & $\frac{\cong}{\stackrel{\Xi}{\Xi}}$ & 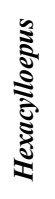 & & & \\
\hline 1 & 532 & $\mathrm{X}$ & & & & & $\mathrm{X}$ & & X X & & 4 \\
\hline 2 & 504 & $\mathrm{X}$ & & & & & & & $\mathrm{X}$ & & 2 \\
\hline 3 & 419 & $\mathrm{X}$ & & & & $\mathrm{X}$ & & & & & 3 \\
\hline 4 & 420 & & & $\mathrm{X}$ & & & $\mathrm{X}$ & & & & 2 \\
\hline 5 & 415 & $\mathrm{X}$ & $\mathrm{X}$ & & & & & & & & 2 \\
\hline 6 & 399 & & & & & & & & & & 0 \\
\hline 7 & 381 & & & & & & & & & & 0 \\
\hline 8 & 381 & & & & & & & & & & 0 \\
\hline 9 & 377 & & & & & & & & & & 0 \\
\hline 10 & 374 & & & $\mathrm{X}$ & & & & & & & 1 \\
\hline 11 & 345 & & & & & & & & & & 0 \\
\hline 12 & 345 & & & & & & & & & & 0 \\
\hline 13 & 259 & & & & & & & & & & 0 \\
\hline 14 & 276 & & & $\mathrm{X}$ & & & & & $\mathrm{X}$ & & 2 \\
\hline 15 & 241 & & & & $\mathrm{X}$ & & & $\mathrm{X}$ & & $\mathrm{X}$ & 3 \\
\hline
\end{tabular}

de las estaciones, en tanto que los ortofosfatos, la turbidez, los coliformes totales, el oxígeno disuelto $(\%)$ y la $\mathrm{DBO}_{5}$, entre otros, presentaron coeficientes de variación muy altos (Tabla 5, Figura 1). Según el índice de contaminación por materia orgánica, las estaciones $4,5,6,7,8$, 9 y 11 presentaron pésima calidad del agua (Figura 1).

Tabla 5. Medidas de tendencia de los parámetros físicos, químicos y bacteriológicos

\begin{tabular}{|c|c|c|}
\hline Parámetro & $\begin{array}{c}\text { Media } \\
\text { aritmética }\end{array}$ & $\begin{array}{l}\text { Coeficiente } \\
\text { de variación }\end{array}$ \\
\hline Temperatura $\left({ }^{\circ} \mathrm{C}\right)$ & 26,33 & 0,07 \\
\hline Oxígeno disuelto $\left(\% \mathrm{O}_{2}\right)$ & 43,59 & 0,93 \\
\hline pH (unidades de $\mathrm{pH}$ ) & 6,84 & 0,15 \\
\hline Conductividad eléctrica (uS/cm) & 219,76 & 0,61 \\
\hline Solidos disueltos totales (ppm STD) & 111,40 & 0,53 \\
\hline Turbidez (UNT) & 17,78 & 0,70 \\
\hline Bicarbonatos (mg/L CaCO 3$)$ & 61,07 & 0,77 \\
\hline Nitratos $\left(\mathrm{mg} / \mathrm{L} \mathrm{NO}_{3}^{-}\right)$ & 0,68 & 1,70 \\
\hline Nitritos $\left(\mathrm{mg} / \mathrm{L} \mathrm{NO}_{2}^{-}\right)$ & 0,08 & 1,61 \\
\hline Amonio $\left(\mathrm{mg} / \mathrm{L} \mathrm{NH}_{4}^{+}\right)$ & 4,48 & 1,67 \\
\hline Ortofosfatos (mg/L PO $\left.{ }_{4}^{3-}\right)$ & 8,09 & 2,92 \\
\hline Sulfatos $\left(\mathrm{mg} / \mathrm{L} \mathrm{SO}_{4}^{2-}\right)$ & 20,94 & 0,56 \\
\hline Coliformes totales (NMP/100ml) & 11124502,70 & 2,09 \\
\hline $\mathrm{DBO}_{5-20^{\circ} \mathrm{C}}\left(\mathrm{mg} / \mathrm{L} \mathrm{O}_{2}\right)$ & 25,47 & 1,67 \\
\hline $\mathrm{DQO}\left(\mathrm{mg} / \mathrm{L} \mathrm{O}_{2}\right)$ & 63,53 & 1,08 \\
\hline Tensoactivos aniónicos (mg/L) & 1,20 & 1,64 \\
\hline Zinc (mg/L Zn) & 0,17 & 1,75 \\
\hline Hierro (mg/L Fe) & 1,50 & 0,42 \\
\hline Caudal $\left(\mathrm{m}^{3} / \mathrm{s}\right)$ & 2,68 & 0,47 \\
\hline
\end{tabular}

DBO: demanda biológica de oxígeno

DQO: demanda química de oxígeno 


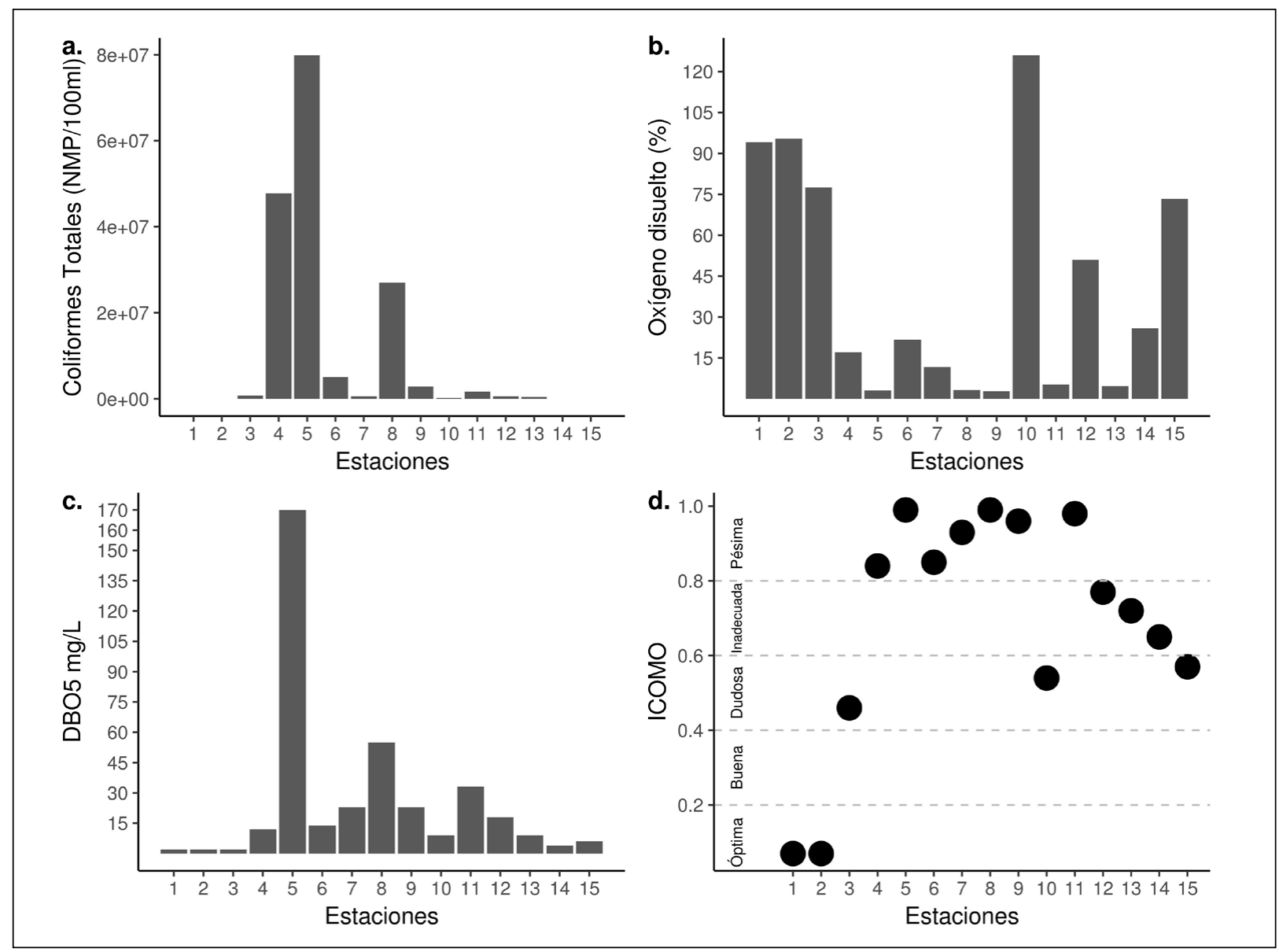

Figura 1. Valores de los registros de a. coliformes totales, b. oxígeno disuelto (\%), c. $\mathrm{DBO}_{5}$, y d. índice de contaminación por materia orgánica (ICOMO), a lo largo de los diferentes puntos de muestreo

Según el análisis de correspondencia canónica (ACC), los parámetros fisicoquímicos y bacteriológicos explicaron el $61 \%$ de la variabilidad biológica durante el periodo de aguas bajas. Las variables con mayor aporte fueron los nitratos, la temperatura, el hierro, los nitritos y el $\mathrm{pH}$, sin embargo, ninguna fue lo suficientemente significativa para explicar el comportamiento de la familia Elmidae en el río Ocoa (prueba de Monte Carlo para el primero y todos los ejes canónicos: $\mathrm{F}=0,000 ; \mathrm{p}=1,00$ ).

A partir del diagrama de ordenación se pudo establecer que los géneros Huleechius, Notelmis y Neoelmis se asociaron con las estaciones 1,2 y 5 y a parámetros como los coliformes totales, la $\mathrm{DBO}_{5}$, la $\mathrm{DQO}$, los sulfatos y el amonio. Microcylloepus se relacionó principalmente con las estaciones 10 y 14 , pero no se asoció claramente con ningún parámetro fisicoquímico. Los géneros Phanocerus, Astrolimnius, Macrelmis y Hexacylloepus se vincularon con las estaciones 3 y 15 y con la variable de turbidez, aunque la longitud del vector fue poca. Se observó una relación inversa entre el cuadrante I (hierro, nitratos, nitritos, temperatura y $\mathrm{pH}$ ) con respecto al cuadrante III (DBO, DQO, amonio, coliformes totales y sulfatos (Figura 2).

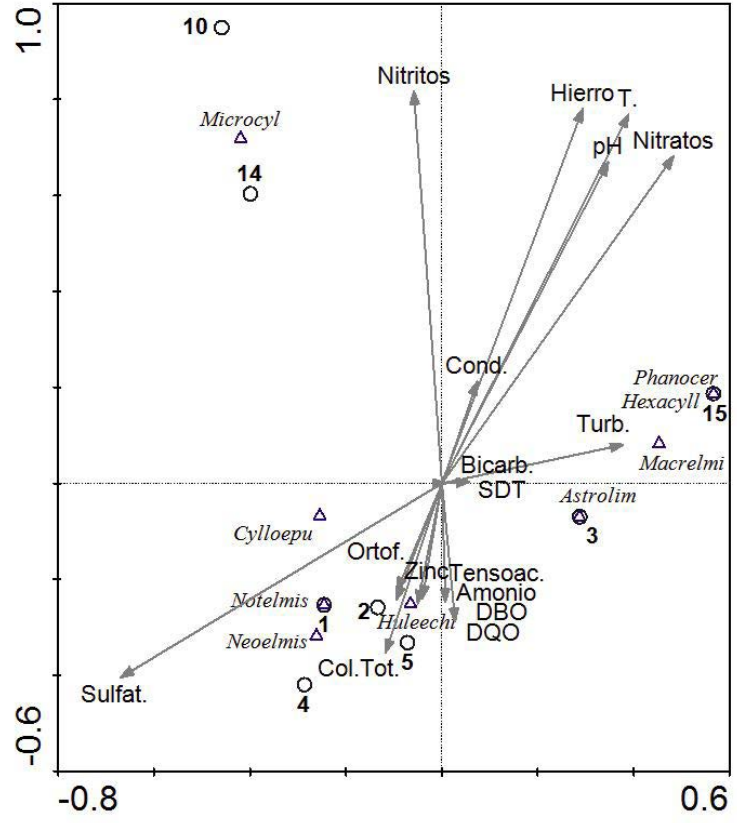

Figura 2. Diagrama de ordenación del análisis de correspondencia canónica (ACC) de los géneros de la familia Elmidae 


\section{Discusión}

Todos los diez géneros de Elmidae encontrados en la cuenca del río Ocoa se encuentran registrados para Colombia en estudios realizados en los departamentos del Valle del Cauca, Antioquia, Norte de Santander, Chocó, Tolima y Caquetá, entre otros (Castellanos \& Serrato, 2008; Posada-García, et al., 2008; Passos, et al., 2010; Llano, 2012; Aguirre-Pabón, et al., 2012; Sondermann, 2013; Zúñiga, et al., 2014; Segura, et al., 2013; GonzálezCórdoba, et al., 2015a, b, 2016 a, b; Mosquera-Murillo \& Córdoba-Aragón, 2015). En lo que respecta a la región de la Orinoquia, en el departamento de Arauca se han registrado 11 géneros (González-Córdoba, et al., 2015a), de los cuales siete se registraron nuevamente en el presente estudio (Heterelmis, Huleechius, Macrelmis, Astrolimnius, Microcylloepus, Cylloepus, Phanocerus), y cuatro no se encontraron (Hexanchorus, Onychelmis, Pseudodisersus y Xenelmis). En Vichada se reportaron recientemente los géneros Hintonelmis y Stegoelmis (González-Córdoba, et al., 2019), y en Meta se conocen diez géneros; Passos, et al., (2010) y Segura, et al., (2013) reportaron los géneros Disersus y Stegoelmis; González-Córdoba, et al., (2015 a,b) registraron Pilielmis, Neolimnius, Hexacylloepus, Microcylloepus, Neoelmis y Xenelmis, y González-Córdoba, et al., (2019) reportaron Gyrelmis e Hyntonelmis. En este trabajo se suman siete nuevos registros, lo que aumenta a 17 los géneros hallados en el departamento del Meta: Austrolimnius, Heterelmis, Cylloepus, Huleechius, Macrelmis, Notelmis y Phanocerus.

Estos registros evidencian que la riqueza genérica de Elmidae con inventario en los ríos de la región es amplia. Por ejemplo, en el río San Juan, departamento de Chocó, inicialmente Mosquera-Murillo \& Córdoba-Aragón (2015) registraron cinco géneros (Heterelmis, Cylloepus, Phanocerus, Macrelmis, Disersus) y, posteriormente, González-Córdoba, et al. (2016b) ampliaron a 11 los géneros de Elmidae registrados (Austrolimnius, Hexacylloepus, Hexanchorus, Microcylloepus, Neocylloepus, Neoelmis). Algo parecido ocurrió en el Valle del Cauca, con muestras de los ríos Anchicayá, Cauca, Dagua y San Juan, y en las regiones naturales andina y pacífica, donde se documentaron 16 géneros en total (González-Córdoba, et al., 2015b). Lo anterior permite concluir que los esfuerzos orientados a registrar la diversidad en corrientes tropicales constituye un aporte efectivo al estudio de la fauna de insectos acuáticos dado que aún se desconoce gran parte de estos organismos en la Orinoquia y no hay información publicada o disponible.

Todavía son muchos los estudios necesarios sobre las fuentes hídricas de la región y el departamento, lo que implica que debe haber una gran riqueza por descubrir, sobre todo si se tiene en cuenta que con el estudio de una sola cuenca urbana se registraron diez géneros, de los cuales siete no se habían registrado antes en el departamento. En este sentido, es previsible que haya un aumento considerable de los registros de Elmidae si se llevan a cabo estudios en las seis grandes cuencas de la región de la Orinoquia: Arauca, Tomo, Vichada, Meta, Guaviare e Inírida, pues conforman un amplio mosaico de ambientes acuáticos naturales y reflejan la gran riqueza de los ecosistemas acuáticos y terrestres (Lasso, et al., 2014; Osorio-Ramírez, et al., 2015).

La gran abundancia y la riqueza del ensamblaje de élmidos en el periodo de aguas bajas puede deberse a las condiciones propicias para el establecimiento de los organismos: la ausencia de cambios bruscos en la estructura física del cauce (sustratos) y una oferta variada y estable de microhábitats (Arias-Díaz, et al., 2007; Lozano, 2014; Serna, et al., 2015; Vásquez, et al., 2014). Sin embargo, es necesario tener presente que la biota acuática soporta diferentes efectos adversos a lo largo de la cuenca (Terneus, et al., 2012; Bielmyer-Fraser, et al., 2017; Martins, et al., 2017; Moreno, et al., 2017; Van, et al., 2017), por ejemplo, la transformación del paisaje con la construcción de vías debida al desarrollo económico en la Orinoquia, y el enriquecimiento orgánico debido a la urbanización, la agricultura y la industrialización (Caicedo, 2016; MoraFernández, et al., 2015; Santana, 2010; Slava, 2015), lo que podría favorecer la aparición de organismos adaptados a estas condiciones. Estos efectos son evidentes durante la sequía (Auble, et al., 1994), lo que refleja que hay ensamblajes específicos frente a los diferentes afectaciones a lo largo del río, aumentando así la riqueza general (Bandyopadhyay \& De, 2017).

Por otra parte, en el periodo de aguas altas los patrones de lluvia se manifiestan de manera intensa y prolongada, cambiando abruptamente la estructura física del cauce, los microhábitats y la biota (Arias-Díaz, et al., 2007; VásquezRamos, et al., 2010; Terneus, et al., 2012; Aguirre-Pabón, et al., 2012; Serna, et al., 2015), lo cual se reflejó en la disminución de la riqueza de Elmidae con el registro de tan solo dos géneros capaces de soportar estas condiciones: Microcylloepus y Heterelmis.

Las características de cada una de las estaciones son de vital importancia para la estructura de los ensamblajes de coleópteros en los ecosistemas lóticos, pues factores como la altura, la intervención antrópica, la vegetación de ribera y la disponibilidad de sustratos, entre otros, determinan los ensamblajes (Velásquez \& Miserendino, 2003; Caupaz-Flórez, et al., 2006; Giraldo, et al., 2014). En el presente estudio se encontró que las estaciones con mayor intervención antrópica y deterioro del hábitat exhibieron la menor abundancia o la ausencia de élmidos (estaciones 6 a 13). Algunos tramos dentro del casco urbano de Villavicencio reciben vertimientos de origen industrial, urbano y minero, entre otros, que podrían alterar la estructura y la composición de las comunidades de macroinvertebrados (Gamboa, et al., 2008; Lozano, 2014; Martins, et al., 2017).

En ese contexto, los géneros reportados se restringieron a ocho de las 15 estaciones, en especial en los primeros tramos del río. La mayor riqueza genérica se evidenció en las estaciones 1 (532 m s.n.m.) y 15 (241 m s.n.m.), lo cual puede atribuirse a que presentaban el menor número de 
afectaciones ambientales y de agentes contaminantes, ya que correspondían a zonas rurales de población reducida, cuyos arroyos son de aguas limpias y presentan una gran oferta de microhábitats, aspectos que favorecen el establecimiento de los coleópteros. Además, los primeros y últimos tramos aún conservan el margen ribereño, por lo que el bosque de ribera sería un componente fundamental de la biota del ambiente acuático y del terrestre, y todos los procesos que se derivan de su interacción (Naiman, et al., 1993; Vidon, et al., 2010).

En las estaciones 1, 2, 3, 4, 5,14 y 15, se registraron 36 individuos debido a una menor presión antrópica inicial sobre el río y al proceso de recuperación en los tramos más bajos cuando el río ha superado la ciudad y sus aportes de materia orgánica y contaminantes para pasar a zonas donde el uso del suelo es principalmente agrícola (Tabla 1).

Algunos tensores ambientales, como la elevada frecuencia de vertimientos domésticos provenientes de la ciudad, las fincas y las casas aledañas, generalmente tienden a disminuir la riqueza de los organismos acuáticos (Figueroa, et al., 2003). En las estaciones donde no se registraron élmidos $(6,7,8,9,11,12$ y 13), tales afectaciones fueron evidentes y los valores del índice de contaminación por materia orgánica fueron altos $(0,7$ unidades, calificación "pésima" e "inadecuada"), debido principalmente al alto contenido de coliformes totales, los cuales están estrechamente asociados con la descarga de aguas residuales de las urbanizaciones (Osorio-Ramírez, et al., 2015), condición que parece incidir de manera directa en los elevados niveles de la $\mathrm{DBO}_{5} \mathrm{y}$ la DQO.

Según Roldán (1999), en situaciones extremas de contaminación orgánica solo se encuentran microorganismos. Además, se ha documentado que factores como el tipo de perturbación antrópica, la naturaleza física del cuerpo de agua y sus condiciones físicoquímicas, tienen un papel crucial en la determinación de la densidad y riqueza de insectos acuáticos en las corrientes (Fossati, et al., 2001; Allan, 2004; Vásquez, et al., 2014). Parámetros como la altitud, el pH del agua, la concentración de oxígeno y la conductividad, así como el uso del suelo, son variables a las cuales los macroinvertebrados acuáticos a menudo responden positiva o negativamente (Ometo, et al., 2000; Arias, et al., 2007).

En los últimos años se han llevado a cabo varios trabajos sobre el orden Coleoptera (García \& Fernández, 1994; Santiago-Fragoso \& Sandoval-Manrique, 2001; Dos Santos, et al., 2011; Epele 6 Archangelsky, 2012; Manzo, 2013; González-Córdoba, et al., 2015 a,b, 2016 a,b, 2019; Mosquera-Murillo \& Córdoba-Aragón, 2015), que han permitido abrir caminos de investigación orientados a establecer su potencial como indicadores de la calidad del agua. En el estudio de Dos Santos, et al., (2011) se concluyó que la familia Elmidae es sumamente sensible a la contaminación y Arias, et al., (2007) relacionaron la presencia de estos organismos con la baja tolerancia a la materia orgánica y las altas concentraciones de oxígeno. En el presente estudio se encontraron asociaciones puntuales entre
Huleechius, Notelmis y Neoelmis y las bajas concentraciones de amonio, coliformes totales, sulfatos $\mathrm{y} \mathrm{DBO}_{5}$, todas ellas indicativas de afectación por vertimientos urbanos (McGrane, 2016) y por actividades agrícolas y ganaderas (Bis, et al., 2000; Figueroa, et al., 2003; Egler, et al., 2012; McGrane, 2016).

Ello permitiría suponer que estos géneros no soportan tales condiciones físicas y químicas del agua y que, además, su presencia dependería de la oferta de alimento, los microhábitats y la estabilidad del sustrato dentro de la corriente. Es importante destacar que en las estaciones 1, 2, $3,4,5$ y 15 , en las que se registraron estos organismos, el amonio estuvo por debajo de $0,1 \mathrm{mg} . \mathrm{L}^{-1}$, en tanto que en las restantes el valor fue superior, probablemente por el uso de fertilizantes nitrogenados y la disposición de excretas y de desechos municipales e industriales (Pacheco, et al., 2002).

Asimismo, estos géneros se asociaron con valores bajos de sulfatos, los cuales se presentaron principalmente en las primeras y últimas estaciones, y fueron abundantes en varias de ellas. Los sulfatos en el agua pueden provenir de aguas residuales industriales (Severiche \& González, 2012) o por drenajes mineros ricos en sulfatos. Zhao, et al., (2017) encontraron que concentraciones superiores a $100 \mathrm{mgL}^{-1}$ representaban un alto riesgo para los macroinvertebrados y los ecosistemas acuáticos; en el presente estudio tales concentraciones fueron inferiores a $50 \mathrm{mg} . \mathrm{L}^{-1}$. No se encontraron otros estudios en los que se relacionara la presencia de la familia Elmidae y de los géneros que la conforman con estas u otras variables fisicoquímicas.

Asimismo, el porcentaje de saturación de oxígeno disuelto varió ampliamente a lo largo de los puntos de muestreo (entre 3 y $120 \%$ ), pero en las estaciones 6, 7, 8, 9, 11,12 y 13 los valores no superaron el $30 \%$, por lo cual no se registraron élmidos. Estas estaciones corresponden propiamente a los tramos más impactados por la urbanización y cuyo grado de contaminación por materia orgánica, según el ICOMO, corresponde a aguas inadecuadas y pésimas (Figura 1). Esto coincide con lo reportado para la mayoría de los macroinvertebrados acuáticos, pues son sensibles a la reducción del oxígeno disuelto, lo que disminuye su riqueza y abundancia e, incluso, llevan a su desaparición (Jacobsen, et al., 2003; Jacobsen, 2008; Rostgaard \& Jacobsen, 2005).

Es importante destacar que se registraron adultos de Huleechius, Heterelmis, Microcylloepus y Cylloepus en las estaciones 4, 5 y 14 cuyos valores de oxígeno disuelto oscilaron entre 3 y $26 \%$ (Figura 1), contrario a lo sugerido por Arias, et al., (2007), quienes registraron la preferencia por corrientes con altos de porcentajes de saturación de oxígeno. Por otra parte, Huleechius y Heterelmis, dos de los géneros más abundantes y de mayor distribución de la familia Elmidae (Braun, et al., 2014; Lozano, 2014; GonzálezCórdoba, et al., 2015b), responden de manera muy variada a las perturbaciones ambientales (Sajami \& Huamantico, 2016; Arias, et al., 2007). Además, es importante resaltar 
que los adultos de estos cuatro géneros se caracterizan por su respiración por plastrón, pues toman el oxígeno atmosférico, se sumergen en el agua e intercambian el gas con el oxígeno disuelto en ella (Brown, 1987), lo cual los hace sensibles a la poca disponibilidad de oxígeno disuelto. Sin embargo, dichos géneros se registraron en las estaciones con tales condiciones (4, 5 y 14), lo que plantea nuevos interrogantes.

Por último, el hierro fue uno de los iones con los que ningún Elmidae presentó asociación, aunque registró valores variables a lo largo de la corriente, y únicamente en las estaciones 1 y 2 no sobrepasó los límites permisibles establecidos por el Decreto 1076 de $2015\left(<1 \mathrm{mgFeL}^{-1}\right)$ para la conservación de la vida acuática; las demás estaciones registraron valores entre 1 y $3 \mathrm{mgFeL}^{-1}$. La carga de hierro ha aumentado en los ecosistemas acuáticos debido a la intensificación de la agricultura, los minerales enriquecidos y los usos silvopastoriles del suelo, y aunque sus efectos sobre los animales acuáticos son principalmente indirectos (osmorregulación, metabolismo, calidad de hábitat y alimentos), pueden actuar en conjunto con otros elementos tóxicos y tener fuertes efectos en la red trófica (Vuori, 1995). En algunos estudios como el de Rasmussen \& Lindegaard (1988) se ha encontrado una correlación negativa entre el hierro disuelto en el agua y la abundancia y riqueza taxonómica de los macroinvertebrados acuáticos: con concentraciones superiores a $0,2 \mathrm{mgL}^{-1}$ la riqueza disminuyó abruptamente y con $>1 \mathrm{mgL}^{-1}$, también la abundancia, en tanto que en concentraciones $>10 \mathrm{mgL}^{-1}$ dominaron las familias Chironomidae, Tipulidae (Diptera) y Tubificidae (Olichochaeta).

Por otra parte, Peters, et al. (2011) han sugerido que pueden haber varios grupos taxonómicos de macroinvertebrados potencialmente afectados por la exposición a bajos niveles de hierro, pues a pesar de que es un ion que se transforma a hidróxidos en condiciones de $\mathrm{pH}>7,0$, estas no cambian significativamente con valores entre 6,5 y 7 , lo que implica que los organismos siguen estando expuestos a la forma del ion. Sin embargo, se requieren más estudios para comprender el impacto ecotoxicológico de todos los factores y usos del suelo que pueden afectar los ecosistemas y los organismos.

\section{Conclusiones}

Se registraron diez géneros de la familia Elmidae en la cuenca del río Ocoa, siete de los cuales son nuevos registros para el departamento del Meta. Los organismos fueron sensibles a la contaminación de origen antrópico y se registró su disminución o ausencia en aquellas estaciones con altos valores de demanda bioquímica de oxígeno y altos contenidos de coliformes totales. Sin embargo, algunos organismos demostraron ser tolerantes a la disminución del oxígeno o al aumento de sulfatos, lo cual evidencia la utilidad de estudios como este para ampliar el conocimiento de la fauna acuática en los diversos ecosistemas acuáticos y aportar información que permita el desarrollo de herramientas de gestión de la biodiversidad en pro de la conservación de la gran riqueza hídrica de la región de los Llanos orientales.

\section{Agradecimientos}

Al Instituto de Ciencias Ambientales de la Orinoquia Colombiana (ICAOC) de la Universidad de los Llanos. Al Proyecto Cuencas, convenio marco de colaboración No. 5211592 de Universidad de los Llanos y Ecopetrol. A Marcela González Córdoba y María del Carmen Zúñiga por su asesoría taxonómica en el laboratorio del Grupo de Investigaciones Entomológicas de la Universidad del Valle. A los integrantes del Grupo de Investigación en Gestión Ambiental Sostenible (GIGAS). El primer autor agradece al proyecto de inversión "Fortalecimiento de las capacidades de investigación en ciencia, tecnología e innovación del departamento del Meta", programa de "Formación del capital humano de alto nivel para el departamento del Meta 2015 - Jóvenes Investigadores" de la Gobernación del Meta. Agradecemos, asimismo, a los revisores anónimos que contribuyeron al mejoramiento de este manuscrito.

\section{Contribución de los autores}

IAAG contribuyó en la formulación del proyecto, la determinación taxonómica, el análisis y la elaboración del manuscrito. JMVR contribuyó en la formulación del proyecto, el análisis de datos y la redacción del manuscrito.

\section{Conflicto de intereses}

Los autores declaran que no existe conflicto de intereses en torno al desarrollo de la investigación.

\section{Referencias}

Allan, J. D. (2004). Landscapes and riverscapes: The influence of land use on stream ecosystems. Annual review of ecology, evolution and systematics. 35: 257-284.

Aguirre-Pabón, J., Rodríguez-Barrios, R., Ospina-Torres, R. (2012). Deriva de macroinvertebrados acuáticos en dos sitios con diferente grado de perturbación, río Gaira, Santa Marta - Colombia. Revista Intropica. 7: 9-19.

Archangelsky, M., Manzo, V., Michat, C., Torres, P. (2009). Coleoptera. En: E. Domínguez y H. R. Fernández, editores. Macroinvertebrados bentónicos sudamericanos. Sistemática y biología. Tucumán, Argentina: Fundación Miguel Lillo. p. 411-468.

Arias-Díaz, D., Reinoso-Flórez, G., Guevara-Cardona, G., Villa-Navarro, F. (2007). Distribución espacial y temporal de los coleópteros acuáticos en la cuenca del río Coello (Tolima, Colombia). Caldasia. 29 (1): 177-194.

Auble, G., Friedman J., Scott, M. (1994). Relating riparian vegetation to present and future streamflows. Ecological Applications. 4: 544-554.

Bandyopadhyay, S., De, S.K. (2017). Spatio-temporal changes in pollution status of the Haora River. En: S. Bandyopadhyay, S. K. De, ditores. Human interference on river health: A study on the Haora River, Tripura, India. Switzerland: Springer International Publishing. p. 169-181.

Bielmyer-Fraser, G., Waters, M., Duckworth, C., Patel, P., Webster, B., Blocker, A., Crummey, C., Duncan, A., Nwokike, S., Picariello, C., Ragan, J., Schumacher, E., Tucker, R., Tuttle, E., Wiggins, C. (2017). Assessment of 
metal contamination in the biota of four rivers experiencing varying degrees of human impact 2017. Environmental Monitoring Assessment. 189: 23-39.

Bis, B., Zdanowicz, A., Zalewski, M. (2000). Effects of catchment properties on hydrochemistry, habitat complexity and invertebrate community structure in a lowland river. Hydrobiologia. 422/423: 369-387.

Braak, C. J. \& Smilauer, P. (2002). CANOCO reference manual and CanoDraw for Windows user's guide: Software for canonical community ordination (version 4.5). Itaca: Microcomputer power.

Braun, B.M., Salvarrey, A.V., Kotzian, C.B., Spies, M.R., Pires, M.M. (2014). Diversity and distribution of riffle beetle assemblages (Coleoptera, Elmidae) in montane rivers of Southern Brazil. Biota Neotropica. 14 (2): e20130001.

Brown, H.P. (1987). Biology of riffle beetles. Annual review of entomology. 32: 253-273.

Caicedo, G. (2016). Perspectivas del desarrollo regional local para la Orinoquia. Orinoquia. 20: 1-3.

Castellanos, P. \& Serrato, C. (2008). Diversidad de macroinvertebrados acuáticos en un nacimiento de río en el Páramo de Santurbán, Norte de Santander. Revista de la Academia Colombiana de Ciencias Exactas, Físicas y Naturales. 32 (122): 79-86.

Caupaz-Flórez, F., Reinoso, R., Guevara, G., Villa-Navarro, F.A. (2006). Diversidad y distribución de la familia Elmidae (Insecta: Coleoptera) en la cuenca del río Prado (Tolima, Colombia). Asociación Colombiana de Limnología-Neolimnos. 1: 106-116.

Chao, A., Gotelli, N. J., Hsieh, T. C., Sander, E. L, Ma, K. H., Colwell, R. K., Ellison A. M. (2014). Rarefaction and extrapolation with Hill numbers: A framework for sampling and estimation in species diversity studies. Ecological Monographs. 84: 45-67.

Dos Santos, D., Molineri, C., Reynaga, M., Basualdo, C. (2011). Which index is the best to assess stream health? Ecological Indicators. 11: 582-589.

Egler, M., Buss, D., Moreira, J.C., Baptista, D.F. (2012). Influence of agricultural land-use and pesticides on benthic macroinvertebrate assemblages in an agricultural river basin in southeast Brazil. Brazilian Journal of Biology. 72 (3): 437-443.

Epele, L. \& Archangelsky, M. (2012). Spatial variations in water beetle communities in arid and semi-arid Patagonian wetlands and their value as environmental indicators. Zoological Studies. 51 (8): 1418-1431.

Ferreira-JR, N., Sampaio, B.H., Fernandes, A.S., Clarkson, B., Braga, R.B., Passos, M.I.S, Santos, A. D. 2014. Ordem Coleoptera. En: Hamada, N., J. L. Nessimian y R. B. Querino, editores. Insetos aquáticos na Amazônia brasileira: taxonomia, biologia e ecologia. Manaus, Brazil: Editora do INPA. p. 349-376.

Figueroa, R., Valdovinos, C., Araya, E., Parra, O. (2003). Macroinvertebrados bentónicos como indicadores de calidad de agua de ríos del sur de Chile. Revista Chilena de Historia Natural. 76 (1993): 275-285.

Fossati, O., Wasson, J., Salinas, C., Marin, R. (2001). Impact of sediment releases on water chemistry and macroinvertebrate communities in clear water Andean streams (Bolivia). Archiv für Hydrobiologie. 151 (1): 33-50.
Gamboa, M., Reyes, R., Arrivillaga, J. (2008). Macroinvertebrados bentónicos como bioindicadores de salud ambiental. Boletín de malariología y salud ambiental. 48 (2): 109-109.

García, F. \& Fernández, M. (1994). Distribución longitudinal de Hydraenidae y Elmidae (Coleoptera) en la cuenca del río Órbigo (León, España). Orsis. 9: 37-57.

Giraldo, L.P., Chará, J., Zúñiga, M. D. C., Chará, A., Pedraza, G. (2014). Impacto del uso del suelo agropecuario sobre macroinvertebrados acuáticos en pequeñas quebradas de la cuenca del río La Vieja (Valle del Cauca, Colombia). Revista Biológica Tropical. 62 (2): 203-219.

González-Córdoba, M., Zúñiga, M. D. C., Torres-Zambrano, N. N., Manzo, V. (2015a). Primer registro de las especies Neolimnius palpalis Hinton y Pilielmis apama Hinton (Coleoptera: Elmidae: Elminae) para Colombia y la cuenca del río Orinoco. Boletín del Museo de Entomología de la Universidad del Valle. 16 (1): 27-33.

González-Córdoba, M., Zúñiga, M D.C., Manzo, V. (2015b). Riqueza genérica y distribución de Elmidae (Insecta: Coleoptera, Byrrhoidea) en el departamento del Valle del Cauca, Colombia. Biota Colombiana. 16 (2): 51-74.

González-Córdoba, M., Zúñiga, M D.C., Manzo, V., Giraldo, L., Chará., J. (2016a). Notelmis Hinton y Onychelmis Hinton (Coleoptera: Elmidae: Elminae) de Colombia: claves taxonómicas ilustradas. Boletín del Museo de Entomología de la Universidad del Valle. 16 (2): 1-17.

González-Córdoba, M., Zúñiga, M. D. C., Mosquera-Murillo, Z., Sánchez-Vásquez, S. (2016b). Riqueza y distribución de Elmidae (Insecta: Coleoptera: Byrrhoidea) en el departamento del Chocó, Colombia. Revista Intropica. 11: 85-95.

González-Córdoba, M., Zúñiga, M. D. C., Manzo, V., GranadosMartínez, C., Panche, J. (2019). Nuevos registros y datos de distribución de diez especies y cuatro géneros de élmidos (Coleoptera: Elmidae) para Colombia. Bol. Cient. Mus. Hist. Nat. U. de Caldas. 23 (1): 247-266. Doi: 10.17151/ bccm.2019.23.1.11.

Gutiérrez-Fonseca, P. (2010). Guía ilustrada para el estudio ecológico y taxonómico de los insectos acuáticos del Orden Coleoptera en El Salvador. En: M. Springer, J. M. Sermeño-Chicas, editores. Formulación de una guía metodológica estandarizada para determinar la calidad ambiental de las aguas de los ríos de El Salvador, utilizando insectos acuáticos. San Salvador, El Salvador: Editorial Universitaria UES. p. 1-64.

Hsieh, T. C., Ma K. H., Chao A. (2019). iNEXT: iNterpolation and EXTrapolation for species diversity. R package version 2.0.19. Fecha de consulta: 13 de marzo de 2019. Disponible en: http://chao.stat.nthu.edu.tw/blog/software-download/

Jäch, M.A., Balke, M. 2008. Global diversity of water beetles (Coleoptera) in freshwater. Freshwater animal diversity assessment. Hydrobiologia. 595: 419-442.

Jacobsen, D., Rostgaard, S., Vásconez, J. (2003). Are macroinvertebrates in high altitude streams affected by oxygen deficiency? Freshwater Biology. 48: 2025-2032.

Jacobsen, D. (2008). Low oxygen pressure as a driving factor for the altitudinal decline in taxon richness of stream macroinvertebrates. Oecologia. 154: 795-807.

Lasso, C., Rial, A., Colonnello, G., Machado-Allison, A., Trujillo, F. (2014). XI Humedales de la Orinoquia (ColombiaVenezuela). Instituto de Investigación de Recursos Biológicos Alexander von Humboldt (IAvH). Bogotá, D. C., 303 p. 
Leps, J., Smilauer, P. (2003). Multivariate analysis of ecological data using CANOCO. Cambridge University Press. New York, $283 \mathrm{p}$.

Lozano, J. (2014). Estudio de la distribución espacial de coleópteros acuáticos en la cuenca del río Alvarado (Tolima, Colombia). Tesis de grado. Universidad de Tolima, Facultad de Ciencias Básicas, Ibagué, Tolima, 96 p.

Llano, C. (2012). Respuesta de los macroinvertebrados bentónicos a las condiciones de calidad de agua en el tramo medioalto del río Felidia, cuenca del río Cali, Valle del CaucaColombia. Trabajo de grado. Universidad Autónoma de Occidente, Santiago de Cali. 102 p.

Manzo, V. (2005). Key to the South American genera of Elmidae (Insecta: Coleoptera) with distributional data. Studies on Neotropical Fauna and Environment. 40: 201-208.

Manzo, V. (2013). Los élmidos de la región Neotropical (Coleoptera: Byrrhoidea: Elmidae): diversidad y distribución. Revista de la Sociedad Entomológica Argentina. 72 (3-4): 199-212.

Martins, R., Couceiro, S., Melo, A., Moreira, M. (2017). Effects of urbanization on stream benthic invertebrate communities in Central Amazon. Ecological Indicators. 73: 480-491.

Mora-Fernández, C., Peñuela-Recio, L., Castro-Lima, F. (2015). Estado del conocimiento de los ecosistemas de las sabanas inundables en la Orinoquia Colombiana. Orinoquia. 19 (2): 254-271.

Moreno, F., Caro, C.I., Pinilla, G.A., Osorio, D.P. (2017). Estado actual del conocimiento sobre microalgas del perifiton y macroinvertebrados bentónicos en el departamento del Meta, Colombia. Acta biol. Colomb. 22 (3): 274-306.

Mosquera-Murillo, Z. \& Córdoba-Aragón, K. (2015). Caracterización de la entomofauna acuática en cuatro quebradas de la cuenca del río San Juan, Chocó, Colombia. Revista de la Academia Colombiana de Ciencias Exactas, Físicas y Naturales. 39 (150): 67-76.

McGrane, S.J. (2016). Impacts of urbanization on hydrological and water quality dynamics, and urban water management: a review. Hydrological Sciences Journal. 61 (13): 2295 2311. Doi: 10.1080/02626667.2015.1128084

Naiman, R.J., Decamps, H., Pollock, M. (1993). The Role of Riparian Corridors in Maintaining Regional Biodiversity. Ecological Applications. 3 (2): 209-212.

Ometo, J., Martinelli, L., Gessner, M.V., Krusche, A., Victoria, R., Cena, M. (2000). Effects of land use on water chemistry and macroinvertebrates in two streams of the Piracicaba River basin, south-east Brazil. Freshwater Biology. 44: 327-337.

Osorio-Ramírez, D., Díaz-Celis, O., Caro-Caro, C.I., DuqueCabrera, J. (2015). Generalidades del área de estudio. En: M. A. Torres-Mora, C. I. Caro-Caro, H. Ramírez-

Gil, S. L. Parada-Guevara, J. M. Trujillo-González, R. E. Ajiaco-Martínez, O. D. Díaz-Celis, editores. Cuenca alta del río Meta: una mirada socioambiental a los ríos Guayuriba y Ocoa y al caño Quenane-Quenanito. Villavicencio, Colombia: Universidad de los Llanos. p. 12-65.

Pacheco, J., Pat, R., Cabrera, A. (2002). Análisis del ciclo del nitrógeno en el medio ambiente con relación al agua subterránea y su efecto en los seres vivos. Ingeniería. 6 (3): 73-81.

Passos, M., Fernández, A., Hamada, N., Nessimian, J. (2010). Insecta, Coleoptera, Elmidae, Amazon region. Check List. 6 (4): 538-545.
Peters, A., Crane, M. Adams, W. (2011). Effects of Iron on Benthic Macroinvertebrate Communities in the Field. Bulletin of environmental contamination and toxicology. 86: 591-595. Doi: 10.1007/s00128-011-0283-2

Posada-García, J., Abril-Ramírez, G., Parra-Sánchez, L. (2008). Diversidad de los macroinvertebrados acuáticos del páramo de Frontino (Antioquia, Colombia). Caldasia. 30 (2): 441-455.

Ramírez, A., Restrepo, R., Viña, G. (1997). Cuatro índices de contaminación para caracterización de aguas continentales. Formulaciones y aplicación. Ciencia, Tecnología y Futuro. 1 (3): 135-153.

Rasmussen, K. \& Lindegaard C. (1988). Effects of iron compounds on macroinvertebrate communities in a Danish Lowland river system. Water Research. 22 (9): 1101-1108. Doi:10.1016/0043-1354(88)90004-8

Roldán, G. (1999). Los macroinvertebrados y su valor como indicadores de la calidad de agua. Revista de la Academia Colombiana de Ciencias Exactas, Físicas y Naturales. 23 (88): 375-387.

Roldán, G. (2016). Los macroinvertebrados como bioindicadores de la calidad del agua: cuatro décadas de desarrollo en Colombia y Latinoamerica. Revista de la Academia Colombiana de Ciencias Exactas, Físicas y Naturales. 40 (155): 254-274.

Rostgaard, S. \& Jacobsen, D. (2005). Respiration rate of stream insects measured in situ along a large altitude range. Hydrobiologia. 549: 79-98. Doi: 10.1007/s10750-005-4165-7

RStudio Team. (2015). RStudio: Integrated Development for R. Studio, Inc., Boston, MA. http://www.rstudio.com/

Sajamí, J.I. \& Huamantinco, A.A. (2016). Distribución espacial de Ephemeroptera, Plecoptera, Trichoptera y Coleoptera (Insecta) en una quebrada de primer orden, bosque montano, Junín, Perú. Revista Peruana de Biología. 23 (2): 95-102. Doi: $10.15381 /$ rpb.v23i2.12377

Salles, F.F. \& Ferreira-Junior, N. (2014). Hábitat e hábitos. En: N. Hamada, J. L. Nessimian, R. B. Querino, editores. Insetos aquáticos na Amazônia brasileira: taxonomia, biologia e ecologia. Manaus, Brazil: Editora do INPA. p. 39-49.

Santana, E. (2010). Editorial: El reconocimiento de la biodiversidad regional. Orinoquia. 14 (1): 1-3.

Santiago-Fragoso, S. \& Sandoval-Manrique, J. (2001). Coleópteros acuáticos y su relación con la dinámica fisicoquímica del río Cuautla (Tramo Tetelcingo-Anenelcuico, Morelos, México). Revista Hidrobiológica. 11 (1): 19-30.

Segura, M.O., Passos, M.I.S., Fonseca-Gessner, A., Froehlich, C. (2013). Elmidae Curtis, 1830 (Coleoptera, Polyphaga, Byrrhoidea) of the Neotropical region. Zootaxa. 3731 (1): 001-057.

Severiche, C. \& González, H. (2012). Evaluación analítica para la determinación de sulfatos en aguas por método turbidimétrico modificado. Ingenierías USBMed. 3 (2): 6-11.

Serna, D., Tamaris-Turizo, C., Gutiérrez, L. (2015). Distribución espacial y temporal de larvas de Trichoptera (Insecta) en el río Manzanares, Sierra Nevada de Santa Marta (Colombia). Revista de Biología Tropical. 63 (2): 465-477.

Sondermann, W. (2013). ¿Está la fauna colombiana de élmidos fuertemente marcada por elementos neárticos? Análisis a distancia de nombres de géneros provistos en 30 inventarios de macroinvertebrados bentónicos recientemente publicados: (Coleoptera: Byrrhoidea: Elmidae). Revista Dugesiana. 20 (2): $251-260$ 
Slava, P.R. (2015). Editorial: ¿Carecemos de inteligencia territorial para promover un modelo productivo responsable en la Orinoquia? Orinoquia. 19 (1): 1-3.

Slipinski, S.A., Leschen, R.A.B., Lawrence, J.F. (2011). Order Coleoptera Linnaeus, 1758. En: Z.Q. Zhang, editor. Animal biodiversity: An outline of higher-level classification and survey of taxonomic richness (Zootaxa, 3148) (203-208). Auckland, New Zealand: Magnolia Press. p. 237.

Terneus, E., Hernández, K., Racines, M. (2012). Evaluación ecológica del río Lliquino a través de macroinvertebrados acuáticos, Pastaza - Ecuador. Revista de Ciencias. 16: 31-45.

Torres-Mora, M., Caro-Caro, C.I., Ramírez-Gil, H., ParadaGuevara, S., Trujillo-González, J., Ajiaco-Martínez, R., Osorio-Ramírez, D., Díaz-Celis, O. (2015). Cuenca alta del río Meta: una mirada socioambiental a los ríos Guayuriba y Ocoa y al caño Quenane-Quenanito. Villavicencio, Colombia: Universidad de los Llanos. p. 172.

Van, K., Piffady, J., Floury, M. (2017). At what scale and extent environmental gradients and climatic changes influence stream invertebrate communities? Science of the Total Environment. 580: 34-42.

Vásquez-Ramos, J., Ramírez-Díaz, F., Reinoso-Flórez, G. (2010). Distribución espacial y temporal de los tricópteros inmaduros en la Ccenca el río Totare (Tolima-Colombia). Caldasia. 32 (1): 129-148.

Vásquez-Ramos, J.M., Guevara-Cardona, G., Reinoso-Flórez, G. (2014). Factores ambientales asociados con la preferencia de hábitat de larvas de tricópteros en cuencas con bosque seco tropical (Tolima, Colombia). Revista de Biología Tropical. 62 (2): 21-40.
Velásquez, S. M. \& Miserendino, M.L. (2003). Análisis de la materia orgánica alóctona y organización funcional de macroinvertebrados en relación con el tipo de hábitat en ríos de montaña de Patagonia. Ecologia Austral. 13: 67-82.

Vidon, P., Allan, C., Burns, D., Duval, T.P., Gurwick, N., Inamdar, S., Lowrance, S., Okay, J., Scott, D., Sebestyen, S. (2010). Hot spots and hot moments in riparian zones: Potential for improved water quality management. Journal of the American Water Resources Association. 46 (2): 278-298.

Von Ellenrieder, N. (2007). Composición y estructura de asociaciones de insectos acuáticos de arroyos de selva nublada de Yungas del NO argentino. Revista de la Sociedad de Entomología de Argentina. 66 (3-4): 57-76.

Vuori, K. (1995). Direct and indirect effects of iron on river ecosystems. Annales Zoologici Fennici. 32: 317-329.

White, D.S., Roughley, R.E. (2008). Coleoptera. En: R.W. Merritt, Cummins, K.W., M.B. Berg, editors. An introduction to the aquatic insects of North America. Iowa, USA: Kendall/ Hunt Publishing Company. p. 571-671.

Zhao, Q., Guo, F., Zhang, Y., Ma, S., Jia, X., Meng, W. (2017). How sulfate-rich mine drainage affected aquatic ecosystem degradation in northeastern China, and potential ecological risk. Science of the Total Environment. 609: 1093-1102.

Zúñiga, M.D.C., Cardona, W., Molineri, C., Mendivil, J., Cultid, C., Chará-Serna, A.M., Giraldo, A. (2014). Entomofauna acuática del Parque Nacional Natural Gorgona, Pacífico colombiano, con énfasis en Ephemeroptera y Plecoptera. Revista de Biología Tropical. 62 (1): 221-241. 